\title{
Retraction Note to: Methylation and Expression Patterns of Tropomyosin-Related Kinase Genes in Different Grades of Glioma
}

\author{
Mahalakshmi Palani $^{1} \cdot$ R. Arunkumar ${ }^{2} \cdot$ Arrambakam Janardhanam Vanisree $^{1}$
}

Published online: 21 August 2021

○) Springer Science+Business Media, LLC, part of Springer Nature 2021

\section{Retraction to: NeuroMolecular Medicine (2014) 16:529-539 https://doi.org/10.1007/ s12017-014-8303-0}

The Editors-in-Chief have retracted this article. Concerns have been raised regarding Fig. 3ii. Specifically, the NTRK1 and NTRK2 panels appear to be unexpectedly similar. The Editors-in-Chief therefore no longer have confidence in the reliability of the data reported in the article.

Arrambakam Janardhanam Vanisree agrees with the retraction but disagrees with the wording of the retraction notice. Mahalakshmi Palani does not agree to this retraction. R. Arunkumar could not be reached for response.
The original article can be found online at https://doi.org/10.1007/ s12017-014-8303-0.

Arrambakam Janardhanam Vanisree vanielango@gmail.com

1 Department of Biochemistry, University of Madras, Guindy Campus, Chennai, Tamil Nadu, India

2 Department of Neurology and Neurosurgery, Madras Medical College, Chennai, Tamil Nadu, India
Publisher's Note Springer Nature remains neutral with regard to jurisdictional claims in published maps and institutional affiliations. 